\title{
Integrated Production and Logistics Planning
}

\author{
https://doi.org/10.3991/ijoe.v14i12.9068 \\ Yassine El Khayyam ${ }^{(凶)}$, Brahim Herrou \\ University Sidi Mohamed Benabdallah, FST, Fes, Morocco \\ y.elkhayyamegmail.com
}

\begin{abstract}
Industrial planning systems have undergone considerable evolution in recent decades, starting from MRP, then ERP, and finally advanced planning and scheduling systems (APS). This evolution took place by dint of the evolution of information and communication technologies, and also due to industrial stakeholder integration tendency forming global supply chains in order to optimize costs and lead times. The purpose of this article is to present a new integrated short and medium term planning approach for upstream logistics (necessary for procurement) and production, this new approach is the MLRP "Manufacturing and Logistic Requirement Planning ". We introduce in this paper a new bill of materials structure that is adapted to the MLRP, and then we present the proposed algorithm which allows determining production and logistics needs for all bills of materials components. Finally, we present the proposed information system that implements the MLRP.
\end{abstract}

Keywords-MRP, production planning, transports planning, integration, MLRP

\section{Introduction}

Industrial planning has gone through several stages, from planning based on forecasting and inventory management to planning that takes into consideration resources and capacity requirements. Industrial planning has also evolved in terms of context, initially performed independently at each supply chain level (supply, production, distribution and sales), to become currently a global supply chain planning [1], which takes into account all the links in the chain as well as the different planning horizons.

The supply chain planning matrix, Fig. 1, considers that any global supply chain could be divided into several internal supply chains; each of these supply chains is composed by four main processes supply, production, distribution and sales [2]. The Materials Requirements Planning (MRP) system is considered the core of all planning and monitoring industrial enterprises systems [3].

We are interested in this article to the integrated planning of production and transport requirements, we present in the first place the evolution of the MRP concept, its limits and the various axes of related researches. Then we present the new method of integrated planning of production and logistics requirements, the MLRP "Manufacturing and Logistic Requirement Planning", next we present the new bills of materials structure adapted to this method. 
We will then expose the developed information system that allows executing MLRP algorithm, generating bills of materials and collecting the data related to master production schedule and available means of transport. Finally, we end with a case study to better expose the MLRP.

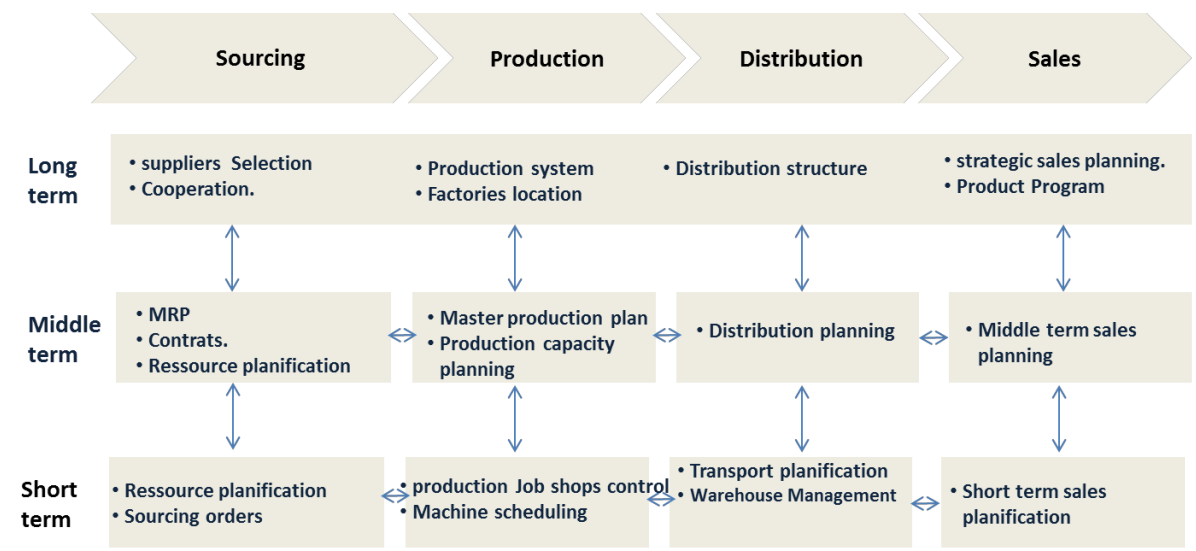

Fig. 1. Supply Chain Planning Matrix

\section{MRP Planning Systems}

\subsection{The MRP concept evolution}

Originally developed in the 1960 s by Orlicky, the MRP "Material Requirement Planning" is founded on the distinction between materials dependent requirements and materials independents requirements. The Orlicky principle [4] is as follows: "The materials independent requirements can only be estimated, by forecasts, and the materials dependent requirements can and must be calculated".

The American Production and Inventory Control Society (APICS) define the MRP as: "a set of techniques that uses bill of materials, inventory levels and master production schedule to calculate material requirements".

The MRP method consists in determining in advance the production orders of components according to the finished products forecast needs, the calculation takes into account lead times to precisely define the components availability date and the date of launching production orders and supply orders [5], Fig. 2 presents the MRP process flow diagram [6].

The MRP [5] calculation is based primarily on the data collection: bill of materials, order book and / or master production schedule, available items quantities and lead times. Then from top level: for each bill of materials level, each component and at each considered period $\mathrm{p}$, repeat:

1. Calculate GRp, the gross requirements at the beginning of period $\mathrm{p}$ : the gross requirements for an item $\mathrm{Y}$ at level $\mathrm{n}$ of bill of materials is the product of planned order 
receipt of (its parent) item $\mathrm{X}$ at higher level n-1 of bill of materials and the assembly coefficient $\mathrm{cm}(\mathrm{Y} / \mathrm{X})$ :

$$
G R_{p}(Y)=P O R_{p}(X, n-1) * c m(Y / X)
$$

2. Calculate available items at the beginning of period $\mathrm{p}$ according to equation (2), where SPp is the expected stock after transactions made during this period. PORp, planned order receipt, is the expected production order or expected supply order that will be received at the beginning of period $\mathrm{p}$.

$$
A D_{p}=S P_{p-1}+P O R_{p}
$$

3. Calculate net requirement, NRp, at the beginning of period according to equation (3)

$$
N R_{p}=\operatorname{Max}\left(0, G R_{p}-A D_{p}\right)
$$

4. Define the orders release dates to satisfy the net requirements by specifying units' quantities and launching date.

5. Calculate the expected stock, SPp, at the end of period p according to equation (4) where PORp, planned order receipt, is the expected production order or expected supply order that will be received at the beginning of period $\mathrm{p}$.

$$
S P_{p}=S P_{p-1}+P O R_{p}-N R_{p}
$$

The MRP implementation as defined becomes more and more complex if the product structure contains several levels and several components, therefrom the fact that MRP systems must be Computer-Assisted [6].

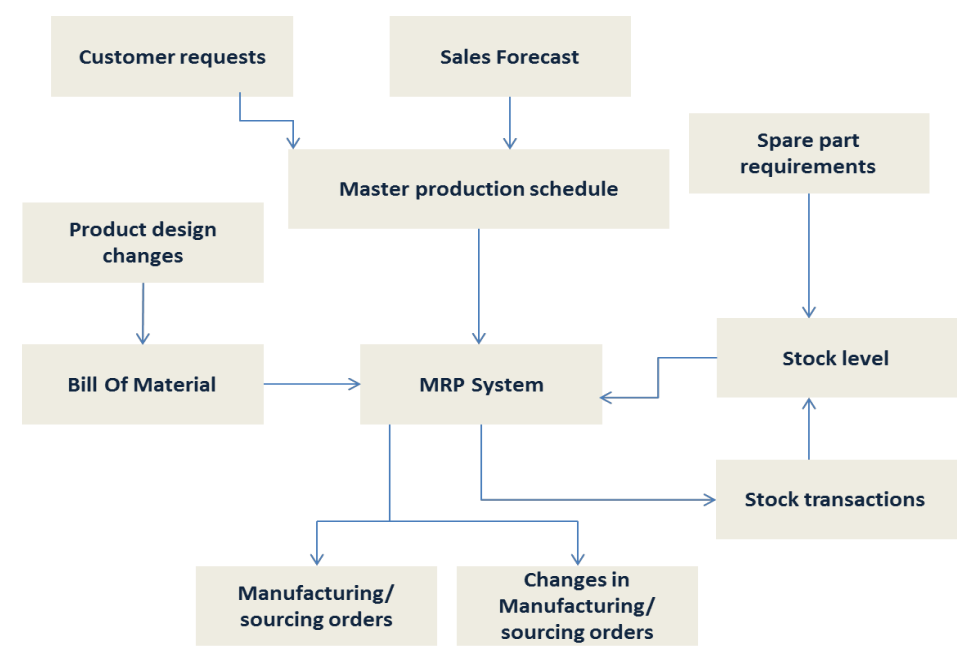

Fig. 2. MRP process flow diagram

MRP is very useful for determining order release dates as well as the necessary components quantities; it is also useful for adjusting planned order release dates after 
deferrals in production or supply lead times. However, the MRP as proposed by Orlicky presents some limitations, among which we cite [6]:

1. Lead times are considered deterministic, which is not the case in reality, production lead times or supply lead times, could be variable as a result of various problems that production, suppliers or even transport means may encounter. Faced with this variability, two alternatives could be made, either set up a security stock or add a security lead time (calculated statistically) to the expected lead time.

2. The product quality supplied by production unit or suppliers is considered perfect (no nonconformities or scraps), which is not the case in reality, in this case the production or supply orders must take into account products supplied quality.

3. The simultaneous MRP implementation for several products which has common components, present some difficulties.

4. MRP does not take into account, in the determination of production or supply orders, capacities of the production units or suppliers.

Faced with these limitations, research was initiated under MRP along two axes. The first research axis could be considered as an extensible research axis that aimed to extend MRP model to a model that takes into account production capacity as well as suppliers capacity, this extension gave rise to the MRP II which provides as outputs not only order release dates but also capacity management plan. This research axis contributes afterward to the development of the ERP which completely revolutionized companies' management [6]. ERP is defined by [7] as: "a software architecture that facilitates information flows management between different functions of an enterprise, it contains a set of activities supported by interconnected application modules that enable the company to manage its planning, inventory management, order tracking, production and maintenance, logistics, finance and human resource management ".

Regarding the second research axis, works focused mainly on improving MRP concept proposed by Orlicky, addressing its main limitations. as to the limitations of MRP model for not taking into account lead times variability and products quality, the literature provides several approaches that address uncertainties in MRP systems, these approaches are based on stochastic inventory control [8], and fuzzy logic [9]. In addition, production capacities, supplier constraints, cost minimization and demand variability are gradually taken into account in mathematical models, [10] provides a mathematical model based on integer linear programming that takes into account manufacturing and supply orders scheduling, production capacities, changes in production plans, storage conditions and costs.

On the other hand, several research works are proposed in the literature to adapt MRP to new production environments by adjusting bill of materials concept, [11] proposes to transform the "make to stock" production system into a "make to order" production system through taking into account finished product customization by producing an adapted bill of material to each personalized product. In parallel, other research works focus on dealing with issues related to MRP and transport management in an integrated way instead of being processed sequentially (one receives outputs from the other as inputs), [3] proposes a conceptual model that integrates production planning and transport planning aspects into a single model, the MRP IV. [12] Proposes a linear 
mathematical programming model based on the proposed Framework by [3], the MRP IV.

\subsection{Discussion}

Except for the works of Mula et al [13 and 3] related to MRP IV as well as those of Diaz-Madronero [12] reelating to the proposal of a linear mathematical programming model based on MRP IV in order to optimize simultaneously costs related to production and transports, integration of transport management into the MRP model is not sufficiently addressed in the literature. We are interested in this paper to the planning integration problematic of production needs and transports needs by proposing a new form of MRP algorithm, the MLRP (Manufacturing and Logistics Requirement Planning). We were inspired by MRP IV Framework [3], Fig. 3, to determine the main parameters of the proposed algorithm and next we used the computation power currently offered by computers to implement the MLRP algorithm.

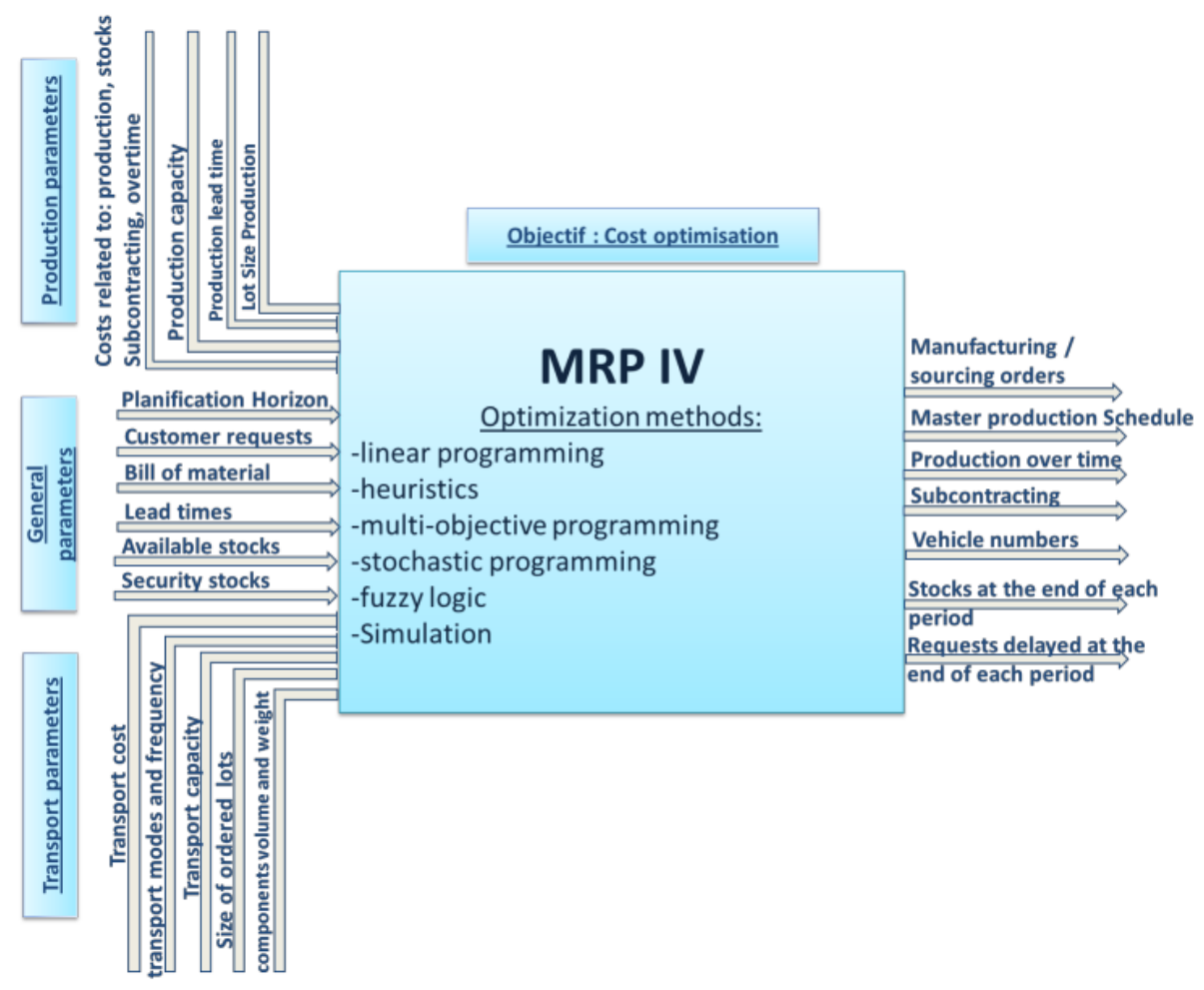

Fig. 3. Framework MRP IV 


\section{$3 \quad$ MLRP: Manufacturing and Logistics Requirement Planning}

In this paragraph, we present the MLRP algorithm which is designed to determine manufacturing and logistics requirements by considering customer requests, bill of material, lead times, components dimensions and weights, volume and maximum weight of the available means of transport, and the transport costs per trip. But before presenting the new algorithm, we will first try to structure the bill of material for MLRP.

\subsection{Structuring bill of material for MLRP}

Bill of material allows specifying how a finished product is made from different parts that go into its composition [14]. It constitutes the product structure technical documentation and allows specifying the relation between the finished product and its components as well as the necessary quantities of each component to produce the finished product [15].

The bill of material can be considered as a graph in which nodes are the components and links are the relationships between each component and the other child components. Finished product is the highest element in the graph; the primary components are components that do not have child components.

The links represent relations between a "parent" component and its components "sons" as well as necessary quantity of each "son" component to realize the parent component, this quantity is called assembly coefficient [14].

In addition to assembly coefficient used to calculate net requirements of each component, MRP in its initial version uses lead times of each component, whether production lead times or supplier lead times, to determine the order release date (production or sourcing).

In order to integrate logistics requirements planning and manufacturing requirements planning, we introduced new parameters to define at the level of each component, these parameters are component volume and weight which are used to determine necessary means of transport, and we also introduced component transport lead times. Fig. 4 shows a bill of material example adapted to the MLR, in which $\mathrm{cm}$ is the assembly coefficient, LT_p is the production lead time, LT_l is the transport lead time, V and W, are component volume and weight and finally SS and S_t0 are safety stock and the initial stock of the component.

To support the creation of finished product bill of material, we have set up a bill of material generator allowing the user, through a web interface, to create bills of materials step by step from the highest level (finished product) to the lowest level. The web interface allows also loading bill of material in XML or JSON format and converting it into a graph such as that of FIG. 4, the associated XML and JSON data is presented in FIG. 5. Bills of materials data are stored in a database in order to be used afterward by the MLRP algorithm. 


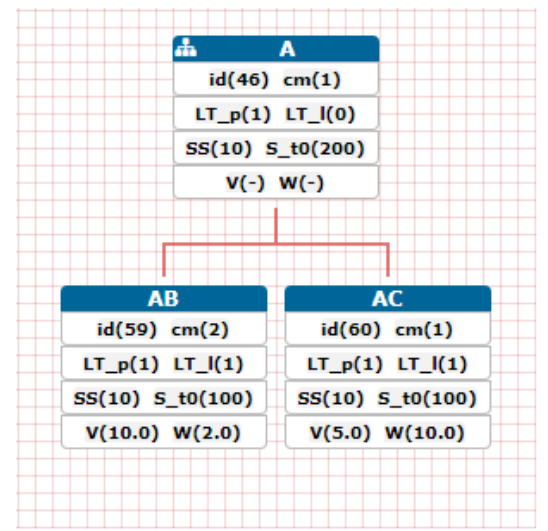

Fig. 4. Bill of material Sample adapted to the MLRP

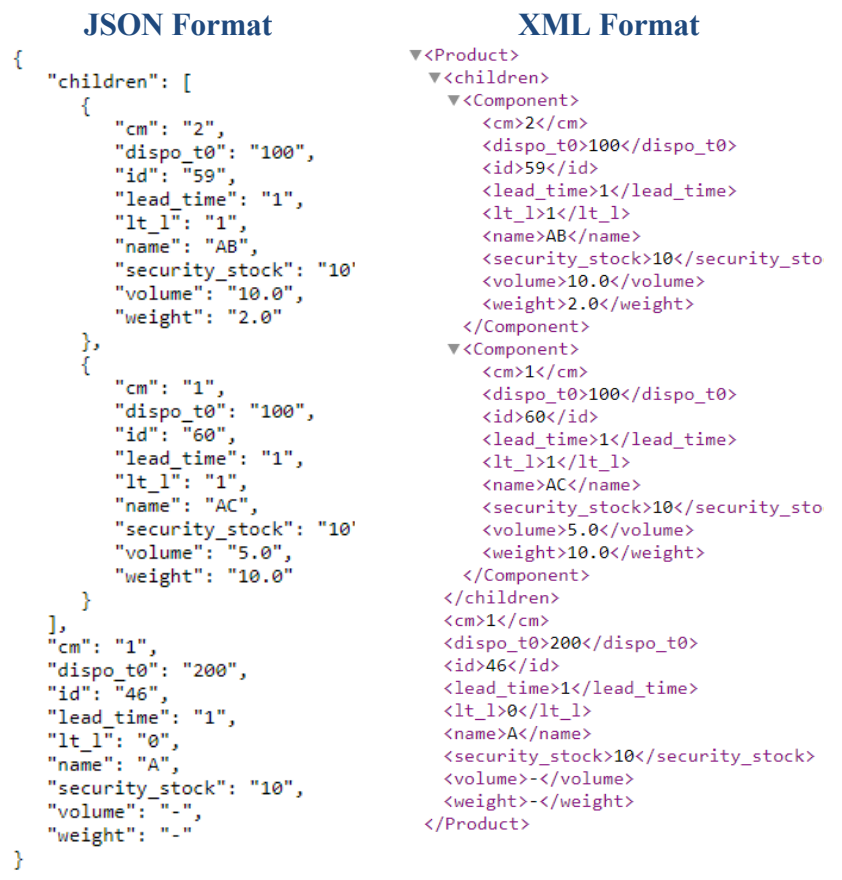

Fig. 5. XML and JSON data examples provided to the BOM generator

\subsection{The MLRP algorithm}

As the MRP algorithm described in the first paragraph, the MLRP consists of iterating over all bill of material levels from the highest level (finished product) to the lowest level. 
For each level "l", each component belonging to level "l" and for each period " $\mathrm{t}$ " in the planning horizon:

1. We determine gross requirements, available stocks and the net requirements for the component. If "l" is relative to the finished product level, the gross requirements are obtained from master production. If no, the gross requirements are obtained by multiplying the parent component net requirements by the assembly coefficient.

2. Once component net requirements are determined for a period $t$, lead times are used to determine order release dates, whether they are production orders or supplier orders.

3. Also based on net requirements and on the elements below, the vehicles required to transport required component quantities are determined.

(a) The component dimensions (volume and weight).

(b) The maximum volume and weight that can support the different means of transport available.

(c) Travel costs per trip for each means of transport.

The data on points $a$ and $b$ above allow us to calculate the maximum number of components that can be carried by each available vehicle, the equation (5) allow to determine this maximum number $\mathrm{Q}_{\mathrm{Ck}, \mathrm{Vi}}$ where Volume $_{\mathrm{vi}}$ is the maximum load volume of the vehicle $\mathrm{Vi}$ and Volume $\mathrm{ck}_{\mathrm{k}}$ is the volume occupied by a component $\mathrm{Ck}$. In the same way Weight $_{\mathrm{vi}}$ is the maximum weight that the vehicle Vi can carry and Weight ${ }_{\mathrm{ck}}$ is the weight of the component $\mathrm{Ck}$

$$
\mathrm{Q}_{\mathrm{Ck}, \mathrm{Vi}}=\min \left(\frac{\text { Volume }_{\mathrm{vi}}}{\text { Volume }_{\mathrm{ck}}}, \frac{\text { Weight }_{\mathrm{vi}}}{\text { Weight }_{\mathrm{ck}}}\right)
$$

Then we proceed to the decomposition of the net requirements of the component $\mathrm{Ck}$ on the different $\mathrm{Q}_{\mathrm{Ck}, \mathrm{Vi}}$ in order to obtain a result in the form of equation (6) specifying the number of vehicles required per type of vehicle.

$$
\mathrm{aV}_{1} \& \mathrm{bV}_{2} \& \ldots \ldots \& \mathrm{nV}_{\mathrm{i}}
$$

Finally, and for the purpose of optimizing transport costs, the net requirements for a given component and a given period is decomposed on all scenarios for the use of possible means of transport. ( $\{\mathrm{V} 1\},\{\mathrm{V} 1, \mathrm{~V} 2\},\{\mathrm{V} 1, \mathrm{~V} 3\} \ldots\{\mathrm{V} 1, \mathrm{~V} 2, \mathrm{~V} 3 \ldots \mathrm{Vi}\})$ Then we evaluate the cost of each scenario to choose the least costly scenario.

\section{$4 \quad$ MLRP Implementation}

To implement the MLRP algorithm, we used the JAVA/J2EE technology to develop a web application which determines manufacturing and logistics requirements by taking into account the bill of material (adapted to the MLRP), the master production schedule and data related to available logistics. 


\subsection{Description the developed information system}

The developed application consists of three modules:

1. Bill of material generation module.

2. Module allowing the data collection related to master production schedule, and those related to the means of transport (available volume, maximum weight, cost/travel).

3. Computation module that implements the previously detailed algorithm.

Bill of material generation module is detailed in section 3.1. Regarding the collection of data related to the master production schedule (gross requirements per period), and those related to the different types of means of transport (type, capacity, cost), we have set up an interface allowing the user to introduce these different data, Fig. 6 "master schedule".

Finally the third module supports execution of MLRP algorithm, taking into account the different data related to the master production schedule and logistics as well as bill of material to determinee for each component order release dates (quantities and dates) and the necessary means of transport.

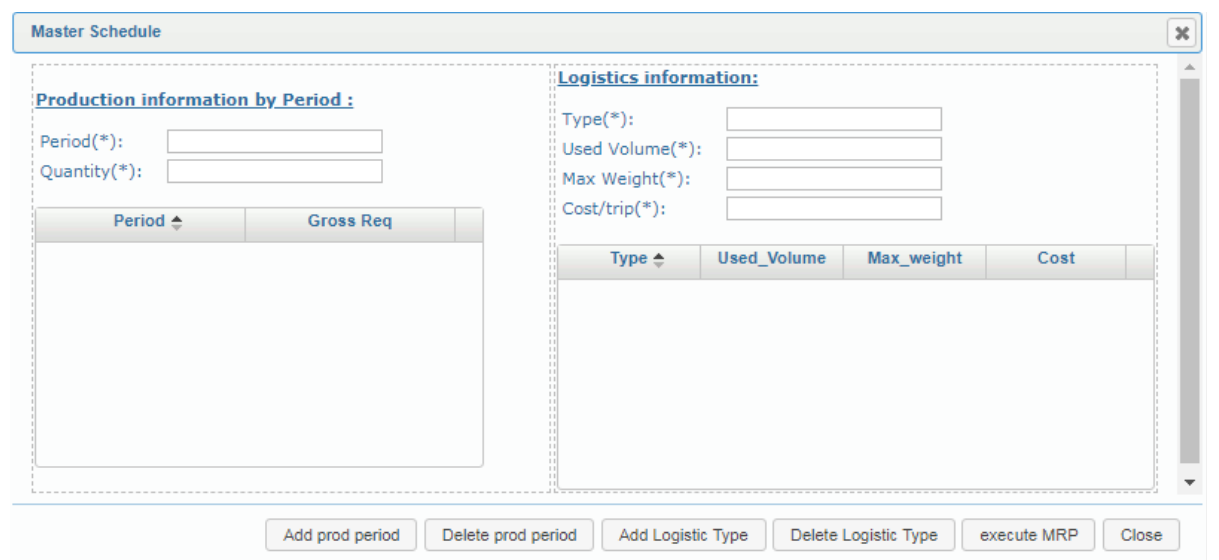

Fig. 6. Master Schedule

\subsection{Case Study}

To illustrate the MLRP execution, we present in this paragraph a use case.

E is a chairs sales specializing company, Fig. 7 presents sold chairs structure. Company E produces back chair and the seat. The bars are supplied by a supplier F1 and the bolts are supplied by the supplier F2. 


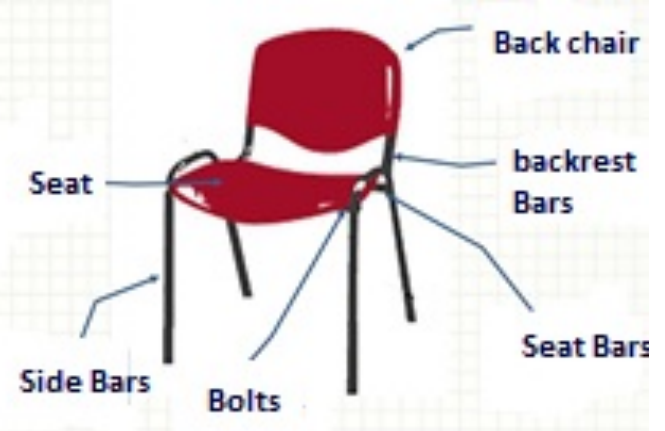

Fig. 7. Chair structure

Company E manufactures the seat or back chair in a day and assembles all items in one day. We have then LT_p $=1$ and LT_l $=0$ for the chair and LT_p $=1$ and LT_l= 0 also for the seat and the chair back.

The supplier F1 requests 3 days as lead time to manufacture the various bars and does not support their transport. Company E needs a day to pick up the bars. In this case the delivery times of the bars are LT $\_p=3$ and LT $1=1$.

The supplier F2 handles bolts delivery within 2 days, in this case the transport lead time is integrated in the supply lead time: $\mathrm{LT}_{-} \mathrm{p}=2$ and LT $1=0$ for the bolts.

By introducing the previous data in the BOM generator, we will have the bill of material below, Fig. 8. Volumes are in liters and weights are in kilograms.

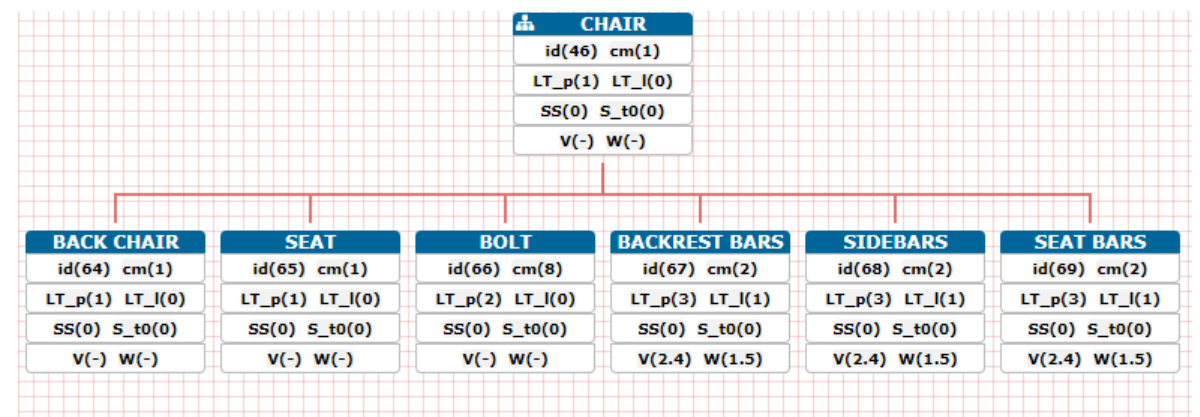

Fig. 8. Chair bill of material (adapted to the MLRP)

The data related to the master production schedule and those related to the available means of transport are introduced in the module "master schedule", Fig. 9 shows us that company $\mathrm{E}$ has orders of 1000 chairs on day 5 and 500 chairs on day 7. It has also the choice between the uses of two types of vehicles R Kangoo or R Master, the R Kangoo can support a weight of $635 \mathrm{~kg}$ and has a useful volume of $2600 \mathrm{l}$ while the R master can support a weight of $2100 \mathrm{~kg}$ and has a useful volume of 108001. 


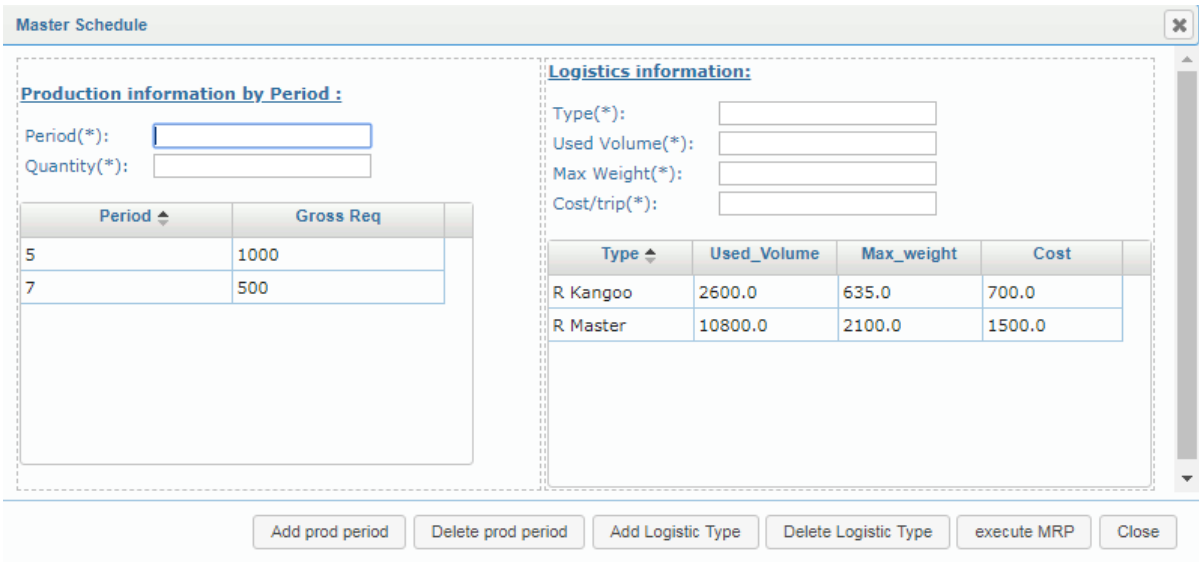

Fig. 9. Master Schedule (Enterprise E)

The MLRP execution allows us to obtain the displayed results in Fig. 10, which indicate that the company must launch production and sourcing orders, it must also have following means of transport:

1. Day 0: make 3 orders to the F1 supplier: 2000 backrest bars, 2000 seat bars and 2000 sidebars.

2. Day 2: make 3 orders to the F1 supplier: 1000 backrest bars, 1000 seat bars and 1000 sidebars. Also order 8000 bolts from supplier F2.

3. Day 3: launch the production order of 1000 seats and 1000 back chairs and expect to have $3 \mathrm{R}$ Master and $5 \mathrm{R}$ Kangoo to retrieve bars.

4. Day 4: start assembling 1000 chairs and order 4000 bolts from supplier F2.

5. Day 5: launch the production order of 500 seats and 500 back chairs and expect to have $3 \mathrm{R}$ Master to retrieve bars.

6. Day 6: start assembling 500 chairs.

\section{Conclusion}

We have introduced in this article a new tool for industrial planning, The MLRP, allowing determining over a horizon planning the different requirements related to production and logistics. This tool is mainly based on the bill of material generator, adapted to the MLRP, and on the data related to master production schedule and the available means of transport.

The MLRP as presented in this article does not take into account production capacity and costs, which can be incorporated later in future research. 
Paper- Integrated Production and Logistics Planning

\begin{tabular}{|c|c|c|c|c|c|c|c|c|}
\hline Period & o & 1 & 2 & 3 & 4 & 5 & 6 & 7 \\
\hline \multicolumn{9}{|l|}{ ¿CHAIR } \\
\hline Gross Req & - & - & - & - & 0 & 1000 & 0 & 500 \\
\hline On Hand Inventory & - & - & - & - & 0 & 0 & 0 & 0 \\
\hline Net Req & - & - & - & - & 0 & 1000 & 0 & 500 \\
\hline Planned order receipt & - & - & - & - & 0 & 1000 & 0 & 500 \\
\hline Production ORD & - & - & - & - & 1000 & 0 & 500 & 0 \\
\hline Logistic ORD & - & - & - & - & & & & \\
\hline \multicolumn{9}{|l|}{ BACK CHAIR } \\
\hline Gross Rea & - & - & - & 0 & 1000 & 0 & 500 & 0 \\
\hline On Hand Inventory & - & - & - & 0 & 0 & 0 & 0 & 0 \\
\hline Net Req & - & - & - & 0 & 1000 & 0 & 500 & 0 \\
\hline Planned order receipt & - & - & - & 0 & 1000 & 0 & 500 & 0 \\
\hline Production ORD & - & - & - & 1000 & 0 & 500 & 0 & 0 \\
\hline Logistic ORD & - & - & - & & & & & \\
\hline \multicolumn{9}{|l|}{ BACKREST BARS } \\
\hline Gross Req & 0 & - & 0 & 0 & 2000 & 0 & 1000 & 0 \\
\hline On Hand Inventory & 0 & - & 0 & 0 & 0 & 0 & 0 & 0 \\
\hline Net Req & 0 & - & 0 & 0 & 2000 & 0 & 1000 & 0 \\
\hline Planned order receipt & 0 & - & $\circ$ & 0 & 2000 & 0 & 1000 & 0 \\
\hline Production ORD & 2000 & - & 1000 & 0 & 0 & 0 & 0 & 0 \\
\hline Logistic ORD & & - & & $\begin{array}{l}1 . R M s \\
: 100 \% \\
1 . R \mathrm{Ka} \\
: 100 \% \\
1 . \mathrm{Ka} \\
: 41 \% \\
41 \%\end{array}$ & & $\begin{array}{l}\text { 1.R Mo } \\
: 71 \%\end{array}$ & & \\
\hline \multicolumn{9}{|l|}{ BOLT } \\
\hline Gross Req & - & $\cdot$ & 0 & - & 8000 & 0 & 4000 & 0 \\
\hline On Hand Inventory & - & - & 0 & - & 0 & 0 & 0 & 0 \\
\hline Net Req & - & - & 0 & $\cdot$ & 8000 & 0 & 4000 & 0 \\
\hline Planned order receipt & - & - & 0 & - & 8000 & 0 & 4000 & 0 \\
\hline Production ORD & - & - & 8000 & - & 4000 & 0 & 0 & 0 \\
\hline Logistic ORD & - & - & & - & & & & \\
\hline \multicolumn{9}{|l|}{$\square$ SEAT } \\
\hline Gross Rea & - & - & - & 0 & 1000 & 0 & 500 & 0 \\
\hline On Hand Inventory & - & - & - & 0 & 0 & 0 & 0 & 0 \\
\hline Net Rea & - & - & - & 0 & 1000 & 0 & 500 & 0 \\
\hline Planned order receipt & $\cdot$ & - & - & 0 & 1000 & 0 & 500 & 0 \\
\hline Production ORD & - & - & - & 1000 & 0 & 500 & 0 & 0 \\
\hline Logistic ORD & - & - & - & & & & & \\
\hline \multicolumn{9}{|l|}{ SEAT BARS } \\
\hline Gross Req & 0 & - & 0 & 0 & 2000 & 0 & 1000 & 0 \\
\hline On Hand Inventory & 0 & - & 0 & 0 & 0 & 0 & 0 & 0 \\
\hline Net Rea & 0 & - & 0 & 0 & 2000 & 0 & 1000 & 0 \\
\hline Planned order receipt & 0 & - & 0 & 0 & 2000 & 0 & 1000 & 0 \\
\hline Production ORD & 2000 & - & 1000 & 0 & 0 & 0 & 0 & 0 \\
\hline Logistic ORD & & - & & $\begin{array}{l}1 . R \mathrm{Ma} \\
: 100 \% \\
1 . R \mathrm{Ka} \\
: 100 \% \\
1 . \mathrm{Ka} \\
: 41 \%\end{array}$ & & $\begin{array}{l}\text { 1.R Mo } \\
: 71 \%\end{array}$ & & \\
\hline \multicolumn{9}{|l|}{ ESIDEBARS } \\
\hline Gross Rea & 0 & - & 0 & 0 & 2000 & 0 & 1000 & 0 \\
\hline On Hand Inventory & 0 & - & 0 & 0 & 0 & 0 & $\circ$ & 0 \\
\hline Net Rea & 0 & - & 0 & 0 & 2000 & 0 & 1000 & 0 \\
\hline Planned order receipt & 0 & - & 0 & 0 & 2000 & 0 & 1000 & 0 \\
\hline Production ORD & 2000 & - & 1000 & 0 & 0 & 0 & 0 & 0 \\
\hline Logistic ORD & & - & & $\begin{array}{l}1 . R \mathrm{Ma} \\
: 100 \% \\
1 . \mathrm{Ka} \\
: 100 \% \\
1 . \mathrm{Ka} \\
: 41 \%\end{array}$ & & $\begin{array}{l}\text { 1.R Mo } \\
: 71 \%\end{array}$ & & \\
\hline
\end{tabular}

Fig. 10. MLRP Results 


\section{$6 \quad$ References}

[1] J. Rohde et al, Die supply Chain Planning Matrix. PPS Management, 5(1), 10-15, 2000.

[2] H. Stadtler et al, Supply Chain Management and Advanced Planning, Springer Texts in Business and Economics, (C) Springer-Verlag Berlin Heidelberg 2015.

[3] J.Mula et al, A Conceptual Modelfor Integrating Transport Planning: MRP IV, IFIP In-ternational Federation for Information Processing pp. 54-65, 2012

[4] J. Orlicky, Material requirements planning. New York: McGraw-Hill, 1975.

[5] L.Boyer et al, Précis d'organisation et de gestion de la production, Éditions d'Organi-sation, 1982.

[6] P. Vrat, Just-in-Time, MRP, and Lean Supply Chains,Materials Management, Springer Texts in Business and Economics 2014.

[7] Shankar R, Jaiswal S (1999) Enterprise resource planning. Galgotia, New Delhi

[8] Barba-Gutiérrez, Y., Adenso-Díaz, B.: Reverse MRP under uncertain and imprecise demand. The International Journal of Advanced Manufacturing Technology 40(3), 413-424 (2009) https://doi.org/10.1007/s00170-007-1351-y

[9] J. Mula et al, MRP with flexible constraints: A fuzzy mathematical programming ap-proach. Fuzzy Sets and Systems 157(1), 74-97 (2006). https://doi.org/10.1016/j.fss.2005.05.045

[10] R. Karni, Integer linear programming formulation of the material requirements plan-ning problem. Journal of Optimization Theory and Applications 35(2), 217-230 (1981). https://doi.org/10.1007/BF00934577

[11] R. Jans et al, Modeling industrial lot sizing problems: a review. International Journal of Production Research 46(6), 1619-1643 (2008). https://doi.org/10.1080/0020754060090 2262

[12] M. Díaz-Madro-ero et al, A mathematical programming model for integrating produc-tion and procurement transport decisions, Applied Mathematical Modelling 52 (2017) 527-543. https://doi.org/10.1016/j.apm.2017.08.009

[13] N. Absi, S. Kedad-Sidhoum, The multi-item capacitated lot-sizing problem with set-up times and shortage costs. European Journal of Operational Research 185(3), 1351-1374 (2008). https://doi.org/10.1016/j.ejor.2006.01.053

[14] H.M.H. Hegge, J C. Wortmann, Generic bill-of-material: a new product model, Inter nattonat Journa 1 of Production Economics, 23 (1991 ) 117-128.

[15] S. Raharno, YY. Martawirya, Improvement of the bill of materials (BOM) generator for product variants. ASEAN Eng J 2012; 3(2): 32-45.

\section{$7 \quad$ Authors}

Yassine El Khayyam is an industrial engineer, currently $\mathrm{PhD}$ student at the industrial techniques laboratory, University Sidi Mohamed Benabdallah, Fes, Morocco.

Brahim Herrou is $\mathrm{PhD}$ and engineer in maintenance and mechanics, teacher and researcher of industrial engineering and maintenance in University Sidi Mohamed Benabdallah, Fes, Morocco.

Article submitted 18 June 2018. Resubmitted 20 September 2018. Final acceptance 29 September 2018. Final version published as submitted by the authors. 